\title{
Location Decision Variations of Japanese Investors in China
}

\author{
Shaoming Cheng ${ }^{*}$
}

ABSTRACT. This paper presents an empirical examination of Japanese investors' location decisions in China and variations in those decisions. The mixed logit model, a recent advancement in discrete choice models, is adopted for the first time in plant location literature by virtue of its superior ability to accommodate heterogeneity. The paper is also intended to propose and establish a systematic method to detect heterogeneity in location choice situations.

Keywords: FDI, Location Choices, Mixed Logit Model

JEL Classifications: F21, L20, R30

\section{INTRODUCTION}

China literally opened its doors to foreign direct investment (FDI) in 1978; three decades later, China has become the top FDI destination country in the world. At the core of China's amazing performance of FDI attraction and utilization are China's FDI preferential policies, which complement its unbalanced development strategy. These policies have given development priorities to either favored industries, such as high-technology sectors, or preferred geographic areas, such as the coastal region. Unfortunately, these preferential policies have resulted in significant regional disparities in China due to its government's emphasis on development along the country's east coast. In order to reduce these disparities, China launched its "Western Development Strategy" in 1997 by shifting the emphasis of FDI preferential policies on to China's vast interior areas. As a result, preferential treatments to targeted industries and areas are increasingly used in China's interior regions in order to boost economic growth by taking advantage of FDI inflows.

This idea that the government is capable of designing tailored policies for a particular industry or region rests squarely on the assumption that some potential policy recipients will respond to a given policy measure. A brief glance at the history of FDI in China suggests substantial uniformity in firms' responses. As China turns ever more frequently toward crafting policies that have greater spatial and industrial focus, it has become of paramount importance to test and verify whether there is variation in firms' responses. Unfortunately, the detection and verification of such variation has been largely ignored. Without the validation of the decision variation, some policies may be ineffective.

This paper addresses this policy question by considering spatial determinants of foreign industrial operations, the efficacy of public policy in the location choice process, and the potentially different reactions of foreign investors toward any given policy. Important and profound evidence is consequently presented on the relationship between public policy and FDI as well as between public policy and industrial plant selection. The study intends to help China's

\footnotetext{
* Assistant Professor, Department of Public Administration, Florida International University, Miami, FL 33199. Email: scheng@fiu.edu

(C) Southern Regional Science Association 2010.

ISSN 1553-0892

SRSA, 1601 University Avenue, PO Box 6025, Morgantown, West Virginia 26506-6025, USA.
} 
policy makers understand what drives foreign investors' location choices and how they react differently with regard to specific policy issues and behavior. This understanding may help China's national, provincial, and local governments establish, refocus, and refine their FDI attraction strategies. Japanese investors and related Japanese greenfield manufacturing FDI have been selected as an example in this paper in order to demonstrate the proposed methodology. The rest of the paper is organized as follows. In the next section, previous empirical and quantitative evidence on the geographic distribution of FDI in China is reviewed; in the third section, the methodology and major data sources used in the paper are introduced. These are followed by primary empirical findings and major conclusions.

\section{LITERATURE REVIEW}

\subsection{FDI Location Determinants in China}

Earlier research in FDI in China focused mainly on its volume and sectoral character or distribution (e.g., Kueh, 1992; Lee and Cheong, 1999; OECD, 2002; Schroath, Hu, and Chen, 1993; Zhang, 1994). While limited compared to other assessments of FDI, previous empirical analyses on the location determinants of FDI in China have been conducted using both aggregate and disaggregate methodologies and their applicable FDI datasets. In the aggregate approach, an ordinary least squares (OLS) method has typically been used with either FDI inflow or stock data (e.g., Broadman and Sun, 1997; Fu, 2000; Gong, 1995; Qu and Green, 1997; Zhao and Zhu, 2000). Disaggregate methodologies, however, were not applied until recently. In the disaggregate approach, each individual firm's location choice is examined, based upon profit maximization, against observable location characteristics such as infrastructure capacity or labor cost. Typically, the conditional logit model has been used in firm-level analyses (e.g., Cheng, 2006; Cheng and Stough, 2006; He, 2003).

Both at the intercity and interprovincial levels, consensus has developed and evolved in the aggregate and disaggregate studies. At the city level, the literature supports positive relationships between FDI distribution and the level of infrastructure, market potential, and preferential policies (Gong, 1995; Qu and Green, 1997; Zhao and Zhu, 2000). At the province level, transportation and communication infrastructure, market size, and policy incentives have been identified as important location determinants for incoming FDI (Broadman and Sun, 1997; Fu, 2000; Fung, Iizaka, and Parker, 2002; Sun, Tong, and Yu, 2002; Wei et al., 1999). Agglomeration economies are also viewed as a significant FDI location factor in China both at the intercity and at the interprovincial levels (Belderbos and Carree, 2002; Broadman and Sun, 1997; Cheng and Kwan, 2000; He, 2003; Qu and Green, 1997; Wei et al., 1999). In addition, labor quality is another principal location determinant. Superior labor quality is a significant draw for FDI (Cassidy, 2002; Cheng and Stough, 2006; Sun, Tong, and Yu, 2002; Wei et al., 1999; Yang, 2002; Zhao and Zhu, 2000).

Despite the general consensus on FDI location determinants in China, the effects of labor cost on the foreign investors' location choices are still mixed. This discrepancy appears across methodological boundaries and therefore arises independent of the specific methods used in the analyses. Consistent with conventional wisdom, higher labor costs of a region are found to be a deterrent to FDI (Belderbos and Carree, 2002; Cheng and Kwan, 2000; Coughlin and Segev, 2000a; Fung, Iizaka, and Parker, 2002; Wei and Liu, 2001). However, Zhao and Zhu (2000) identify a positive correlation between high labor cost and FDI attraction. To reconcile this result, Zhao and Zhu note that absolute wage levels can be a misleading labor-cost indicator 
because of various levels of labor productivity. That is to say, high wages can be interpreted either as an indicator of expensive labor cost or as an indicator of a productive labor force. Consequently, the labor-cost measurement is refined from absolute wage levels to effective wage levels, which is the ratio between absolute wages and labor productivities. Cassidy (2002) and Wei et al. (1999) employ the effective wages and conclude that foreign investors avoid Chinese provinces with higher effective wages. The heated debate on the impacts of labor costs on FDI distribution in China, however, has been fueled by He (2001) who finds that foreign investors choose Chinese provinces with higher effective wages. He hypothesizes that this positive correlation may result from an association of high labor quality with costly labor. Cheng (2006) empirically tests this high labor quality hypothesis and finds that high labor quality does, to a great extent, explain the positive correlation between effective wages and FDI attraction in China. That is to say, by spatially locating in high-wage areas, foreign investors tap into larger pools of high quality labor.

With regard to the location choices of Japanese FDI in China, many studies emphasize that Japanese FDI displays a distinctive location pattern. Schroath, Hu, and Chen (1993) show that Japanese firms tend to be concentrated in China's northeast to exploit the region's geographic and cultural factors. Zhao and Zhu (2000) argue that Japanese FDI pursues resources while American and European FDI chase higher labor productivity and strong local economic bases. Cheng and Stough (2008) and Zhou, Delios, and Yang (2002) find Japanese FDI nationality-specific agglomeration Nationality-specific FDI clustering by Japanese firms was also found in Europe and the United States (Ford and Strange, 1999; Head, Ries, and Swenson, 1995, 1999; Smith and Florida, 1994).

\subsection{Heterogeneity in Discrete Choice Models}

Discrete choice models in economics have generally been grounded on the assumption of a "representative" decision maker. A representative individual is assumed to have typical tastes-equal to the average preferences across all decision makers - with regard to any given observed attribute (Hausman and Wise, 1978). Hence, homogenous preferences are assumed across the entire population of decision makers toward any given observed characteristic. Of course, decision makers are different and they have different preferences. Their varied preferences are rooted deeply in cultural, socioeconomic, and organizational environments (BenAkiva and Lerman, 1985). Without recognizing and properly controlling for preference heterogeneity, significant biases may be introduced into the estimation of discrete choice models (Boxall and Adamowicz, 2002). For example, the "representative" approach may not be appropriate if the decision makers’ preferences are very polarized or highly spread out.

The representative approach also dominates in industry location studies in general and in FDI location research in particular. The representative approach suggests an average production function across individual firms, regardless of their sizes, sectors, management strategies or goals, and other different characteristics. The representative production function dictates an "average" or representative firm's location decision which maximizes the firm's profits. Consequently, the representative approach assumes that firms would respond homogenously to the increase of land price or changes in other location factors in their location decisions.

Heterogeneity has then been gradually added into discrete choice models, primarily in social science literature. One way to include and examine preference heterogeneity is through interaction terms between various observed factors, such as individual-specific income levels 
(Adamowicz et al., 1997; Morey, Rowe, and, Watson, 1993; Massey, 2002). These different preferences, which are associated with observable characteristics, are often referred to as observed heterogeneous preferences. Alternatively, the observed preference heterogeneity can be incorporated through stratified model estimation. Specifically, the same discrete choice estimation is repeated in a variety of strata, which are created, if not arbitrarily or presumptively, in line with demographic or socio-demographic characteristics, in order to show taste variation between the demographic or social groups (Boxall, Adamowicz, and Tomasi, 1996; Famulari, 1995). The incorporation of the observable preference variation, however, requires a priori knowledge on the selection of individual-specific or demographic factors (Boxall and Adamowicz, 2002). These selections are often limited to a few socioeconomic attributes due to the inadequate understanding of potential sources of heterogeneity, i.e., unavailable or untested $a$ priori knowledge.

Besides observed heterogeneous preferences that result from observed factors, preference variations can also arise from unobserved individual characteristics. These variations accordingly are often referred to as unobserved preference heterogeneity. The essential difference between the observed and unobserved preference heterogeneity is that researchers do not have any a priori information on the potential sources of the unobserved taste variation. Unobservable preference variation had not been successfully integrated into discrete choice analysis until the recent breakthrough and development of the mixed logit model. By using a random parameter approach, the mixed logit model is able to detect the existence of preference heterogeneity (Hensher and Greene, 2003; Train, 1998, 2003).

\subsection{Heterogeneity in FDI Location Studies}

Previous literature on FDI location determinants paid little attention to the potential heterogeneity in foreign investors' location choices. The most common approach used to investigate the various preferences in foreign investors' location choices is to contrast their choices according to FDI nationalities in any given country (e.g., He, 2003; Fung, Iizaka, and Parker, 2002). It has been widely held that FDI from different origin countries may show variations in spatial distribution. These distinctive geographic differences are included in the socalled "country-of-origin" effects. Another common practice used to test for potential heterogeneity is to distinguish new FDI ventures from FDI acquisitions in any given country (e.g., Friedman, Gerlowski, and Silberman, 1992; Ó Huallcháin and Reid, 1997). Since new ventures are also called "greenfield investments," possible location decision differences derived from this greenfield-acquisition divide are also referred to as greenfield investment effects.

Beyond the efforts to tease out the "country-of-origin" and "greenfield investment" effects, research on heterogeneity and location decision variations toward given location determinants is scarce. Most studies that have examined such location variations focus on the characteristics of foreign firms, such as their different sizes or industrial configurations. Unfortunately, these studies show mixed results. Using a conditional logit model, Head, Ries, and Swenson (1999) fail to find support for cross-industry variation in Japanese investors' location decisions in the United States. This contrasts with Belderbos and Carree (2002) who, also applying a conditional logit approach, found that small Japanese firms are more likely to geographically follow their predecessors' location decisions than their bigger counterparts. With

Southern Regional Science Association 2010. 
a hazard model, Gross, Raff and Ryan (2004) show that Japanese firms are more likely to be spatially proximate to keiretsu member firms, i.e., keiretsu-specific agglomeration. ${ }^{1}$

The mixed results do not necessarily mean that there is no heterogeneity in foreign investors' location choices. Instead, these conflicting results may only suggest that the criteria used to distinguish one group of foreign investors from another may not be valid. The inadequate attention to heterogeneity and these mixed results, to a great extent, occur because of a lack of a readily adoptable research method for the examination of heterogeneity and for the comparison of various research findings. Therefore, one crucial goal of this paper is to apply an updated discrete choice methodology to test for heterogeneity, in hopes of establishing a systematic methodological approach.

\section{METHOD AND DATA}

\subsection{Method}

The mixed logit model, a recent advance in discrete choice modeling, is designed to overcome the limitations of the conditional/multinomial logit model. The mixed logit model provides an effective solution to relax the independence of irrelevant alternatives (IIA) property and its associated rigid proportionate substitution pattern in the conditional logit model (McFadden and Train, 2000). It is important to note that applications of the mixed logit model were not fully explored until the development of simulation techniques and fast computers in the late 1990s. More recently, it has been used to investigate choice behavior in such fields as transportation (Bhat, 1998), multiparty elections (Glasgow, 2001), recreation demands (Train, 1998), and household's appliance choices (Revelt and Train, 1998).

The mixed logit model can be derived from either the "random coefficients" specification or the "error components" specification. The two derivations are mathematically equivalent but subject to different interpretations (Hensher and Greene, 2003; Train, 2003). The choice of one specification over the other depends on whether the purpose of the study is to examine substitution patterns or to reveal random taste variation (Glasgow, 2001). This study adopts the random coefficient specification due to its ability to uncover the heterogeneity of decision makers.

In the random coefficient specification, the mixed logit model differs from the conditional logit model in terms of the specification of the parameters. Like the conditional logit model, the mixed logit model decomposes the decision maker's utility into a representative profit function and a disturbance factor, $\pi_{i j}=\beta_{i}^{\prime} X_{i j}+\varepsilon_{i j}$. Unlike the conditional logit model where parameters, $\beta_{i}$, are fixed across decision makers to capture the average or representative individual preferences regarding a given characteristic, the mixed logit model allows its parameters, $\beta_{i}^{\prime}$, to vary across decision makers in order to incorporate preference variation.

Among the variable parameters, $\beta_{i}^{\prime}$, for each decision maker whose preferences are $\beta_{i}$, his/her probability of choosing alternative $j$ out of $J$ potential provinces in the standard conditional logit model is:

\footnotetext{
${ }^{1}$ A keiretsu refers to a set of companies with interlocking business relationships and shareholdings and is almost exclusively a concept pertaining to Japanese business culture.
} 


$$
\operatorname{Pr} o b\left(j \mid \beta_{i}\right)=\frac{\exp \left(X_{i j} \beta_{i}\right)}{\sum_{s=1}^{J} \exp \left(X_{i s} \beta_{i}\right)}
$$

However, because researchers cannot observe every $\beta_{i}$ of each decision maker, the parameters, $\beta_{i}^{\prime}$, are specified to follow a pre-determined distribution. The choice probability then becomes the integral of the conditional probability over all possible $\beta_{i}$ :

$$
P_{i j}=\int\left[\frac{\exp \left(X_{i j} \beta_{i}^{\prime}\right)}{\sum_{s=1}^{J} \exp \left(X_{i s} \beta_{i}^{\prime}\right)}\right] f(\beta \mid \theta) d \beta
$$

where $f(\beta \mid \theta)$ is the density of the distribution of $\beta^{\prime}$, and $\theta$ are the parameters of the distribution, such as the mean and standard error. One of the challenges for estimating the mixed logit model is to identify the appropriate preference distribution (Hensher and Greene, 2003). With regard to the preference distribution, $\beta^{\prime}$ has been specified as normal or lognormal (Revelt and Train, 1998; Train, 1998), triangular or uniform (Hensher and Greene, 2003).

The choice probability in equation (2) for any given $f(\beta \mid \theta)$ can be approximated by simulation-assisted estimation methods (Train 2003). Draws are taken from the distribution $f(\beta \mid \theta)$ to represent the values of $\beta^{\prime}$. For each draw $\beta^{r}$, its conditional probability $\operatorname{Pr} o b_{i j}^{r}\left(j \mid \beta^{r}\right)$ is calculated. The simulated choice probability on the basis of repeated draws is:

$$
S P_{i j}=\frac{1}{R} \sum_{r=1}^{R} \operatorname{Pr} o b_{i j}^{r}\left(j \mid \beta^{r}\right)=\frac{1}{R} \sum_{r=1}^{R} \frac{\exp \left(X_{i j} \beta^{r}\right)}{\sum_{s=1}^{J} \exp \left(X_{i s} \beta^{r}\right)}
$$

where $S P_{i j}$ is the simulated estimator and $R$ is the total number of draws. The simulated choice probability $S P_{i j}$ is then introduced into the log-likelihood function $L L(\beta)=\sum_{i=1}^{N} \sum_{j=1}^{J} y_{i j} \ln P_{i j}$, obtaining the simulated log likelihood:

$$
S L L=\sum_{i=1}^{N} \sum_{j=1}^{J} y_{i j} \ln S P_{i j}
$$

where $y_{i j}$ equals one if decision maker $i$ chooses alternative $j$ and zero otherwise.

The maximum simulated likelihood estimator for $\theta$ of preference distribution density $f(\beta \mid \theta)$ is the value that can maximize SLL in equation $4 .{ }^{2}$ In the simulation-assisted estimation process, the parameters of the distribution, $\theta$, typically means and standard deviations, can be estimated. From the means, the standard deviations, and the pre-determined parameter

\footnotetext{
${ }^{2}$ Parameter estimation was conducted in NLOGIT 3.0, a recent supplement to LIMDEP 8.0.
} 
distribution, researchers are able to detect and verify the existence of preference variation and estimate the percentage of population that like and dislike any particular decision factor (Brownstone and Train, 1999). For example, for any given normally distributed coefficient, if its mean is 1.0 and standard deviation is 2.0 , then about 70 percent of the entire population in question is in favor of this particular characteristic and the rest dislike it.

In any mixed logit model estimation, at least one explanatory variable must be assumed to be fixed, i.e., free of heterogeneity, in order to substantially reduce the prohibitively high computational burdens of the model (Hensher and Greene, 2003). Cost or price variables are typically ideal candidates for being fixed variables in mixed logit models (Train, 2003). This is because fixed cost or price variables make it convenient for researchers to calculate the so-called "willingness-to-pay" ratio, which is the ratio between any explanatory variable and a cost or price variable. In addition, Hensher and Greene also proposed that researchers should be able to determine the fixed variables based on their own research.

\subsection{Data}

This paper focuses primarily on Japanese greenfield manufacturing FDI and its location preferences within China for four reasons. First, this will eliminate the "country-of-origin" effect, which usually refers to preference differences among FDI from various origins. This effect may arise from economic, geographic, and cultural factors (Kogut and Singh, 1988; Lecraw, 1993; Luo, 2000). Second, Japan, one of the earliest FDI home countries in China, has been the second largest origin of FDI in China. Japan's long investment history and its vast investments in China generate a coherent and abundant data source, allowing researchers to investigate the long-term location patterns and changes of Japanese FDI in China. In addition, compared to manufacturing FDI, service FDI in China is only allowed in a few designated cities. These highly regulated location choices of service FDI are beyond the scope of this study. Fourth, greenfield FDI, i.e., new plants, is more capable of revealing the true location preferences of foreign investors than FDI plants that arise from mergers or acquisitions. This is because the location decisions in mergers and acquisitions, in most cases, would be determined by the supply of available merger or acquisition candidates (Coughlin and Segev, 2000a; Little, 1978, 1980; Woodward, 1992). While the findings and conclusions from the exclusive examination on Japanese FDI may not be directly generalized to FDI location choices of other countries, the method employed in the paper is novel and can be used to examine FDI from different origins.

Compatible with the disaggregate mixed logit model, this paper uses disaggregate firmlevel Japanese FDI data (Toyo Keizai Inc., 2003), which are available from "Kaigai Shinshutsu Kigyou Souran” (Japanese Overseas Investment), the result of Toyo Keizai Inc.'s yearly survey of Japanese overseas subsidiaries worldwide. Yamawaki (1991) suggested that this publication approximates the population of Japanese firms' overseas affiliations. In its 2003 edition, 764 in the period of 1997 to 2002 are listed. In addition, detailed information for each affiliate is also provided on its city and provincial location, the year founded, major business and industry, and whether it is a greenfield investment or the result of a merger or acquisition. In the period of 1997-2002, six provinces failed to have a new Japanese new manufacturing plant, so these provinces are excluded from the choice sets accordingly (see Table 1). The exclusion of these provinces with no Japanese manufacturing establishment is primarily because any choice alternative must be chosen at least once for logit models to be used (Ben-Akiva and Lerman, 1985; Friedman, Gerlowski, and Silberman, 1992). 
Table 1: Provincial Distribution of Japanese Plants in China

\begin{tabular}{llll}
\hline \hline Beijing & 22 & Henan & 7 \\
Tianjin & 33 & Hubei & 1 \\
Hebei & 17 & Hunan & 2 \\
Shanxi & 0 & Guangdong & 115 \\
Neimenggu & 2 & Guangxi & 0 \\
& & Hainan & 1 \\
Liaoning & 46 & & \\
Jilin & 4 & Chongqing & 6 \\
Heilongjiang & 4 & Sichuan & 8 \\
& & Guizhou & 2 \\
Shanghai & 190 & Yunnan & 1 \\
Jiangsu & 172 & Xizang & 0 \\
Zhejiang & 54 & & \\
Anhui & 5 & Shaanxi & 7 \\
Fujian & 20 & Gansu & 0 \\
Jiangxi & 2 & Qinghai & 0 \\
Shangdong & 42 & Ningxia & 1 \\
& & Xinjiang & 0 \\
\hline \hline
\end{tabular}

Source: “Kaigai Shinshutsu Kigyou Souran.” 2003.

This dataset has many attributes that make it superior to data sources used in similar analyses. First, this dataset for the first time differentiates greenfield FDI from acquisition FDI in China. Unlike earlier studies focusing on general FDI distribution in China, this study explicitly excludes acquisition FDI from its analysis and therefore significantly improves the data quality. Second, this dataset is in a better position than prior ones to control the influences resulting from a blurring of the FDI nationality. This dataset relies on Japanese official sources, which exclusively survey Japanese enterprises on their overseas investment activities. This differs entirely from previous data sources, which depend on China's custom statistics that fail to take into account the real nationality of foreign investing firms. Third and final, the dataset intentionally avoids dividing itself into arbitrary and presumptive sub-groups based on certain firm characteristics, e.g., sizes and industrial configurations. Instead, this dataset retains sufficient variation among the individual Japanese firms by intentionally including seemingly different Japanese investors, and therefore enables researchers to apply the new methodological approach and to verify the existence of heterogeneous preferences in location choices when some “obvious” preference heterogeneity sources are present.

The dependent variable in this paper is a province's probability of being chosen out of the 25 alternative Chinese provinces. Each Japanese greenfield manufacturing plant is treated as an independent observation, in which 25 alternative provinces are assumed to be considered. A score of one will be assigned to the selected provincial choice while a score of zero is assigned to the rest of alternatives. As a result, each observation depends on the location attributes of the chosen provinces and all the non-chosen ones. 
Table 2: Descriptions of Independent Variables and Their Expected Signs

\begin{tabular}{|c|c|c|c|}
\hline $\begin{array}{l}\text { Independent } \\
\text { Variables } \\
\end{array}$ & Descriptions & $\begin{array}{l}\text { Expected } \\
\text { Sign } \\
\end{array}$ & Sources \\
\hline Market potential & Provincial GDP per capita in 1997 & + & Statistical Yearbook \\
\hline Infrastructure & $\begin{array}{l}\text { Provincial transportation length per } \\
\text { capita in } 1997\end{array}$ & + & of China \\
\hline Labor cost & $\begin{array}{l}\text { Provincial effective manufacturing } \\
\text { wages in } 1997\end{array}$ & - & \\
\hline Land cost & $\begin{array}{l}\text { Provincial average house prices per } \\
\text { square meter in } 1997\end{array}$ & - & \\
\hline Labor quality & Provincial adult illiteracy rate in 1997 & - & \\
\hline $\begin{array}{l}\text { Non-nationality } \\
\text { agglomeration }\end{array}$ & $\begin{array}{l}\text { Provincial percentages of Chinese } \\
\text { domestic enterprises' output in } 1997\end{array}$ & + & \\
\hline Geographic size & Provincial total population in 1997 & + & \\
\hline $\begin{array}{l}\text { State-Owned } \\
\text { Enterprises }\end{array}$ & $\begin{array}{l}\text { Provincial percentages of SOEs' } \\
\text { industrial output in } 1997\end{array}$ & - & \\
\hline Nationality & Provincial location quotients of & & Yearbook of China's \\
\hline agglomeration & Japanese FDI in 1997 & + & $\begin{array}{l}\text { Foreign Economic } \\
\text { Relations and Trade }\end{array}$ \\
\hline $\begin{array}{l}\text { Length of } \\
\text { openness }\end{array}$ & $\begin{array}{l}\text { Operating time of each province's } \\
\text { first national development zone } \\
\text { up to } 2001\end{array}$ & + & $\begin{array}{l}\text { China's Association } \\
\text { of Development Zones } \\
\text { www.cadz.org.cn }\end{array}$ \\
\hline
\end{tabular}

Independent variables used in previous studies are integrated into the empirical analysis of this paper to ensure consistency and comparability with prior research. Any difference in findings between this research and earlier ones would be attributed to the new research approach in this paper instead of the selection of variables. A total of ten independent variables are used and their measurements are determined based on the literature. These variables are market potential, infrastructure capacity, labor and land costs, labor quality, nationality and non-nationality agglomeration, the concentration of state-owned enterprises (SOEs), policy variables, and geographic size (see Table 2). Summary statistics of the independent variables are shown in Table 3.

Table 3: Summary Statistics of Independent Variables

\begin{tabular}{lcccc}
\hline \hline & Mean & Std. Dev. & Min. & \multicolumn{1}{l}{ Max. } \\
\hline Market potential & $2,856.7$ & $1,933.4$ & 210.9 & $7,315.5$ \\
Infrastructure & 11.86 & 5.01 & 4.33 & 24.02 \\
Labor cost & 574.38 & 160.06 & 353.36 & 956.66 \\
Land cost & 1,043 & 420 & 654 & 2,321 \\
Labor quality & 0.137 & 0.048 & 0.068 & 0.231 \\
General agglomeration & 1.067 & 0.914 & 0.198 & 3.881 \\
Nationality agglomeration & 0.003 & 0.005 & 0 & 0.022 \\
State-Owned Enterprises & 0.343 & 0.157 & 0.094 & 0.595 \\
Length of openness & 13.52 & 5.23 & 1 & 22 \\
Geographic size & 206,757 & 237,392 & 6,200 & $1,183,000$ \\
\hline \hline
\end{tabular}


Market Potential. As one of the most important location determinants of FDI in China, market potential has been primarily measured on the assumption that incoming FDI would primarily focus on the provincial market rather than the national one. Fu (2000) argued that the provincial market approach is appropriate because of China's highly segmented markets that resulted from Mao's developmental strategy. Along with this approach, indicators of market size include provincial GDP (Fung, Iizaka, and Parker, 2002; Sun, Tong, and Yu, 2002), provincial GNP (Broadman and Sun, 1997), provincial income per capita (Chen, 1996), and provincial GDP growth (Wei et al., 1999). This paper uses provincial GDP per capita as a proxy for market size in part because the shifting motivation of foreign investors from exports to domestic consumptions_for example, Graham and Wada (2001)_indicated that since 1996 a growing portion of China's FDI has been directed more toward the domestic market instead of exporting processing. A positive sign is expected.

Infrastructure Capacity. In the previous literature, the coverage of infrastructure varies. Some studies exclusively focus on transportation infrastructure (He, 2003; Head and Ries, 1996; Zhou, Delios, and Yang, 2002). Telecommunications and postal services were also considered in some other analyses (Gong, 1995; Wei et al., 1999; Zhao and Zhu, 2000). In these studies, a density indicator on the basis of either population or geographic sizes has been used to measure varied infrastructure capacities. Infrastructure capacity would be critical to Japanese greenfield investment regardless of whether they produce to re-export or to serve China's domestic market. This paper adopts highway density, which is the ratio between a province's total length of roadways and its geographic size, as the indicator. Greater highway density should be more attractive to firms since it would make it easier for them to get their goods to market. Thus a positive relationship is hypothesized between highway density and establishment location.

Costs. Two cost variables are used in the analysis. The first is labor cost. A major difference in a number of previous labor cost measures is the manner in which labor productivity is accounted. Broadman and Sun (1997), Chen (1996), Fung, lizaka, and Parker (2002), Sun, Tong, and Yu (2002), and Zhao and Zhu (2000) used average wages without controlling for labor productivity. Coughlin and Segev (2000b) and Head and Ries (1996) also used average wages but introduced a separate labor productivity variable as well. Cassidy (2002), He (2001), and Wei et al. (1999) employed the effective wage, which is the ratio of average wages to labor productivity, as their indicator of labor cost. Cheng (2006) and Fu (2000) teased out the distraction of agricultural wages by focusing on the manufacturing sector with the effective manufacturing wages. Effective manufacturing wages will be employed here and higher wages are expected to repulse locating firms.

The other cost variable is land cost. As a classical factor in industrial location literature, land cost has been surprisingly left out in analyses on the location determinants of FDI in China. This may be partly because provincial average land prices are generally not available in China. Cheng (2006) and Cheng and Stough (2006) developed an alternative land-cost measurement by using average provincial house prices to approximate average land prices. Cheng argued that it would be dependable since land values make up a large portion of house prices in China. Another advantage of the housing price index is that it captures dramatic changes in housing prices and subsequently land prices in China, particularly in some major cities where Japanese investment is pervasive. This study will borrow Cheng's approximation due to the lack of more reliable data sources. High land costs are expected to deter locating firms. 
Policy Incentives. Dummy variables have been widely used to capture provincial differences resulting from preferential policies (Cassidy, 2002; Gong, 1995; Head and Ries, 1996). Besides dummy variables, Fung, Iizaka, and Parker (2002) differentiate provinces by the number of development zones within them. Fu (2000) constructs a policy advantage index that considers various preferential tax rates and different provincial approval authorities on FDI projects. Cheng (2006), He (2001), and Zhou, Delios, and Yang (2002) consider the operating periods of various development zones along with the numbers of those zones in a province. They argue that the earlier a national development zone was established in a province, the longer the province has been open to foreign investors, and the more likely the province is able to attract foreign investors due to the accumulation of observable and unobservable benefits related to the length and history of openness. This study follows this openness-length approach and assumes a positive sign for the policy variable.

Agglomeration Effects. Two potential agglomeration phenomena are examined. One is Japanese nationality agglomeration and the other is non-nationality agglomeration. Japanese nationality agglomeration refers to the agglomeration of Japanese FDI regardless of the distribution of China's domestic investments, while non-nationality agglomeration means the concentration of Japanese FDI around China's indigenous firms. Japanese nationality agglomeration, i.e., "following the leader" or "following the predecessor" has been extensively documented in previous FDI literature focused on China and in East Asia (e.g., Belderbos and Carree, 2002; Tokunaga and Ishii, 2000). Agglomeration phenomena may arise due to either efficiency considerations (Krugman and Venables, 1995; Marshall, 1920) or "demonstration effects" (Cheng and Stough, 2006; DeCoster and Strange, 1993). However, it is empirically infeasible to distinguish these two types of agglomeration effects (DeCoster and Strange, 1993).

A variety of variables have been used in previous research to capture agglomeration economies. Head and Ries (1996) used industrial output and the count of industrial establishments in the agglomeration economy. He (2001) used provinces' employment location quotients to capture the pulling force of strong local industrial bases. In addition, he used the number of foreign enterprises in the previous year to capture nationality agglomeration. Cheng (2006) and Cheng and Stough (2006) used location quotients of Japanese FDI and Chinese domestic industrial outputs in each province as indicators of nationality and non-nationality agglomerations, respectively. This research continues to use Cheng's location quotient approach. Agglomeration economies are expected to be a locational lure.

Labor Quality. A variety of measures have been adopted to capture the effects of labor quality on incoming FDI. Broadman and Sun (1997) and Coughlin and Segev (2000b) used adult illiteracy level as their cross-sectional indicator of relative labor quality. Sun, Tong, and Yu (2002) measured the relative endowment of skilled workers using counts of scientists, engineers, and technicians per 1,000 employees. Wei et al. (1999) used scientists and researchers as a share of total employment. Cheng and Kwan (2000) used three different labor quality measures, namely, the percentages of the entire population with (1) at least primary school education, (2) at least a junior high education, and (3) at least a senior high school education. Cheng (2006) revised Cheng and Kwan's measures and adopted the percentage of the adult population with at least a junior high education. This study adopts the level of adult illiteracy as an indicator for labor quality. Lower literacy is expected to repel firms.

State-Owned Enterprises. The strength of SOEs in a province has been measured by industrial output (Lu, 1997) or employment (He, 2003). SOE's share of a province's total industrial output 
is used in this paper because employment would likely overestimate the involvement of SOEs in the provincial economy's well-known labor inefficiency. The presence of SOEs in a province is expected to dampen firms' likelihoods of locating there.

Geographic Size. The primary reason to include Chinese provinces' land areas is to control these provinces' various sizes and to show their potential effects on Japanese investors' location choices. Daly (1982) and Hensher (2005) stated that larger geographic alternatives are more likely to be chosen than their smaller counterparts simply because of their bigger sizes, and therefore it would be crucial to properly control the sizes of alternatives in a spatial setting. Because care has been taken to mitigate any effect of geographic size in other independent variables-for example, transportation density and GDP per capita-provincial land area is introduced in order explicitly to capture the effect that may result from the size of Chinese provinces. The literature suggests that provinces with greater land areas are more likely to be selected as locations for new foreign-owned establishments.

\section{EMPIRICAL FINDINGS}

In this section, empirical findings are presented with regard to Japanese manufacturing investors' location decisions among Chinese provinces in the period of 1997-2002. In the model specification, all of the explanatory variables are assumed to follow normal distributions, except geographic size, labor cost, and land cost variables. These three variables are assumed to be free of heterogeneity in order to reduce the specifications' computational burdens.

Interpretation of the estimated coefficients in logit models is not straightforward. This is because logit models are not linear and their estimated coefficients of explanatory factors cannot be directly linked to factors' marginal effects (Ben-Akiva and Lerman, 1985). In order to measure their marginal magnitudes, this paper uses average probability elasticity. The average probability elasticity is the sum of probability elasticity across all individuals and alternatives (He, 2003; Head, Ries, and Swenson, 1995). This elasticity is desirable because it is able to illustrate the population's average response, i.e., average probability, toward any given explanatory variable rather than the reaction of any individual within the population (Train, 1986). This indicator on average probability also complements the analysis on response variation, which emphasizes individually unique and potentially different responses toward a given factor.

The elasticity of the probability of investor $i$ choosing province $j$ with regard to location attribute $X_{k}$ can be calculated as follows:

$$
E_{i j}^{k}=\frac{\partial \operatorname{Pr} o b(j)}{\partial X_{k}} \frac{X_{k}}{\operatorname{Pr} o b(j)}=\beta_{k}[1-\operatorname{Pr} o b(j)]
$$

The average probability elasticity of location attribute $X_{k}$ can then be obtained by summing up all investors $i$ in province $j$.

$$
E^{k}=\sum_{i=1}^{N} \sum_{j=1}^{J} E_{i j}^{k}=\frac{J-1}{J} \beta_{k}
$$

where $J$ is the total number of alternative provinces and $\beta_{k}$ is the estimated coefficient of location attribute $X_{k}$. In this study, Japanese investors face 25 alternative provinces in the period of 1997- 
2002. Consequently, the average probability elasticity of explanatory variable $X_{k}$, its estimated marginal effect, is equal to 96 percent of $\beta_{k}$.

$$
E^{k}=\sum_{i=1}^{N} \sum_{j=1}^{J} E_{i j}^{k}=\frac{J-1}{J} \beta_{k}=\frac{25-1}{25} \beta_{k}=96 \% \beta_{k}
$$

The commonly used goodness-of-fit indicator in logit models is the likelihood ratio index $\rho^{2}$. The index $\rho^{2}$ ranges from zero to one in a similar fashion to that of $R^{2}$ in linear regressions. Although higher $\rho^{2}$ values are clearly preferred, there appears to be no generally accepted rule of thumb for a reasonable level for $\rho^{2}$ (Ben-Akiva and Lerman, 1985). Still, a $\rho^{2}$ in the range of 0.2-0.4 seems to be regarded as an "extremely good model fit" (Louviere,

Hensher, and, Swait, 2000, p. 55). Hensher and Johnson (1981) shared this view and put forward that the relatively low $\rho^{2}$ values result from the nonlinear nature of logit regressions.

\subsection{Evidence on Japanese Investors' Location Choices}

Most of the explanatory factors incorporated into the analysis are statistically significant and have expected signs. Only limited significant variation of Japanese investors in their plant location search is indicated, as most of the standard deviations of parameter distributions are statistically insignificant (see Table 4).

Traditional location factors had an insignificant, if not negligible, influence on Japanese investors. These factors include land cost, labor cost, market potential, and infrastructure capacity. The limited role of these factors may in turn suggest that there are not huge differences among Chinese provinces in terms of these location considerations. Japanese investors thus pay little attention to them in their plant location search in China.

Contrary to the marginal role of those traditional location factors, agglomeration economies significantly shaped Japanese investors' location choices. The variable of Japanese nationality agglomeration is statistically significant and it is estimated that a 10 percent increase in the number of Japanese firms in a province raises its probability of being chosen by over 46.4 percent. This finding strongly supports previous evidence on Japanese investors' tendency to locate spatially proximate to prior Japanese FDI establishments (Belderbos and Carree, 2002; He, 2003). The enormous magnitude of the Japanese nationality effect may come from cluster advantages among Japanese firms in China in anticipating structural changes. Existing Japanese firms in China undoubtedly are principal information sources on China's local economic and regulatory conditions (Belderbos and Carree, 2002). But more importantly, due to the increasing inter-firm connection and interaction in modern manufacturing, it would only make sense for some Japanese firms to locate near their customers and supply chain links, which are already in China.

The other agglomeration factor, general agglomeration, is statistically significant as well. Results suggest that a 10 percent increase in general agglomeration raises a province's chances of being selected as a plant destination by 16.8 percent. The finding echoes earlier conclusions that Japanese investors tend to be geographically close to China's domestic industrial bases 
Table 4: Empirical Results for Japanese FDI Distribution in 1997-2002

\begin{tabular}{|c|c|c|c|}
\hline Variables & Parameter & Value & Significance \\
\hline Market Potential & $\begin{array}{l}\text { Mean of coefficient } \\
\text { Std. dev. of coefficient }\end{array}$ & $\begin{array}{l}0.001 \\
0.759\end{array}$ & $\begin{array}{l}0.000 \\
0.735\end{array}$ \\
\hline Infrastructure Capacity & $\begin{array}{l}\text { Mean of coefficient } \\
\text { Std. dev. of coefficient }\end{array}$ & $\begin{array}{l}0.058 \\
0.003\end{array}$ & $\begin{array}{l}0.106 \\
0.945\end{array}$ \\
\hline Non-Nationality Agglomeration & $\begin{array}{l}\text { Mean of coefficient } \\
\text { Std. dev. of coefficient }\end{array}$ & $\begin{array}{l}1.751 \\
0.010\end{array}$ & $\begin{array}{l}0.025 \\
0.927\end{array}$ \\
\hline Nationality Agglomeration & $\begin{array}{l}\text { Mean of coefficient } \\
\text { Std. dev. of coefficient }\end{array}$ & $\begin{array}{l}4.836 \\
0.259\end{array}$ & $\begin{array}{l}0.000 \\
0.943\end{array}$ \\
\hline State-Owned Enterprises & $\begin{array}{l}\text { Mean of coefficient } \\
\text { Std. dev. of coefficient }\end{array}$ & $\begin{array}{l}-3.125 \\
4.227\end{array}$ & $\begin{array}{l}0.030 \\
0.004\end{array}$ \\
\hline Labor Quality (Illiteracy) & $\begin{array}{l}\text { Mean of coefficient } \\
\text { Std. dev. of coefficient }\end{array}$ & $\begin{array}{l}-16.146 \\
18.271\end{array}$ & $\begin{array}{l}0.000 \\
0.005\end{array}$ \\
\hline Length of Openness & $\begin{array}{l}\text { Mean of coefficient } \\
\text { Std. dev. of coefficient }\end{array}$ & $\begin{array}{l}0.068 \\
0.002\end{array}$ & $\begin{array}{l}0.013 \\
0.939\end{array}$ \\
\hline Land Cost & Mean of coefficient & -0.005 & 0.000 \\
\hline Labor Cost & Mean of coefficient & 0.002 & 0.005 \\
\hline Geographic Size & Mean of coefficient & 0.028 & 0.000 \\
\hline $\begin{array}{l}\text { Summary Statistics } \\
\text { Number of observations } \\
\text { Log likelihood } \\
\text { Likelihood ratio } \chi^{2} \\
\text { Likelihood ratio index } \rho^{2}\end{array}$ & $\begin{array}{l}764 \\
-1762.625 \\
1387.237 \\
0.283\end{array}$ & & \\
\hline
\end{tabular}

(Head and Ries, 1996; Lu, 1997; Qu and Green, 1997). The pursuit of China's local industrial strengths confirms previous literature that elaborates on the importance of localized manufacturing capabilities in the FDI recipient countries (Dunning, 1980, 1998; Kojima, 1978; Smith and Florida, 1994).

The concentration of SOEs in a province adversely and tremendously affects Japanese investors' location interest in it. A 10 percent increase in the proportion of SOEs in the economy of a province will reduce its probability of being chosen by 30 percent. The aversion to China's SOEs echoes the documented findings in earlier studies, which attribute this aversion to China's SOEs' low efficiency, bureaucratic management, and corruption (e.g., He, 2003; Lu, 1997; OECD, 2002). This may imply that reforming SOEs may not only improve their performance but also indirectly help recruit Japanese FDI.

Another factor that discourages Japanese investors is inferior labor quality. It is estimated that a 10 percent higher illiteracy rate in a province will result in a 15.5 percent decline in the probability of being chosen. This also supports previous findings on the adverse relationship between low quality labor force and Japanese FDI recruitment (e.g., Broadman and Sun, 1997; Coughlin and Segev, 2000b; Wei, et al., 1999; Yang, 2002). The pursuit of quality labor or the 
avoidance of an illiterate labor force may also explain why labor cost, or wages, plays a nearly imperceptible role in Japanese investors' plant search efforts in China. Thanks to China's geographically united wage structure, Japanese investors have been able to shop around and indulge themselves with skilled but affordable workers and avoid illiterate labor forces which would be far more difficult to train compared to their higher quality counterparts. The importance of labor quality, along with the marginal effects of traditional location factors, may suggest that Japanese FDI in China is experiencing structural reorientation from resource-based manufacturing to more technology-oriented manufacturing, which relies more heavily on skilled workers.

The policy variable capturing the effects of China's FDI preferential measures is statistically significant and has the expected sign. In terms of its influences, a 10 percent increase in the length of time a province is open to the outside world increases its probability of being selected by about 0.7 percent. This implies that China's FDI preferential policy generates a series of indirect, comprehensive, and lasting impacts on the society and general business practices of the policy recipient provinces or cities, influences that would notably facilitate Japanese investors' business operations. These impacts may include administrative flexibility, general understanding and acceptance of a more market-oriented economy, and greater adherence to rules and regulations (Fu, 2000). These impacts continuously grow as the provinces or cities are exposed to the FDI special treatment and to foreign investors and their practices and operations. As a result, Japanese investors may tend to locate their plants in provinces with a longer openness history.

The geographic size variable, which is intended to control for size variation among the Chinese provinces, is statistically significant and has the expected sign. This may imply that Japanese investors tend to locate themselves in larger provinces, provided other economic and policy conditions are identical. Since the magnitude of the variable is minimal, it suggests that the size differences between Chinese provinces are not a major determining factor in Japanese investors' location decisions.

\subsection{Evidence on the Location Decision Variations of Japanese Investors}

This paper employs a mixed logit model, which is able to empirically reveal potential variation in Japanese investors' location decisions. Even though this approach may not be able to identify specific sources for the variation, it provides a solid methodological and empirical ground for future research on the same topic. This mixed logit approach assumes that all Japanese investors follow a normal response distribution for each location factor. A statistically significant standard deviation for any of these normal distributions suggests the existence of varied responses toward the location factor in question. In addition, the estimated means and standard deviations of parameters also shed light on the proportion of the population of decision makers that place a positive or a negative value on any specific location attribute. Information on population attitude division will help policy makers to better anticipate and evaluate the outcome and effectiveness of any proposed policy initiative.

Among all of the independent variables, two variables, namely SOEs and labor quality, have statistically significant standard deviations for their normal coefficient distributions, indicating that there are variations in these two location attributes. The mixed logit model, unfortunately, is not able to identify the sources of the variations. 
For the varied responses toward Chinese SOEs, under the normal distribution assumption with the estimated mean of (-3.125) and estimated standard deviation of 4.227, it is suggested that 77 percent of the preference distribution is below zero and 23 percent is above. That is to say, 77 percent of Japanese investors regard a high concentration of SOEs as an undesirable location attribute while 23 percent believe otherwise. This aversion to SOE concentration may imply that the majority of Japanese investors are doubtful about the provincial economic health implied by the local dominance of China's SOEs and are therefore reluctant to be spatially proximate to them, if not necessarily avoiding any economic contact with them (Tong and Hu, 2003). This reluctance can also be explained by the observation that some Japanese investors, particularly those with advanced technologies, are intentionally motivated to move away from SOEs to reduce technology or knowledge spillovers and to avoid losing their competitive advantages and creating potential competitors.

Similarly, for the labor quality variable, under the normal distribution presumption with the estimated mean of $(-16.146)$ and estimated standard deviation of 18.271 , it is suggested that 81 percent of the distribution is below zero and 19 percent is above. That is to say, more than three-fourths of Japanese investors appear to avoid provinces with labor forces with low levels of human capital. The variation may be caused by the sectoral composition of Japanese plants in China. Highly routinized manufacturing operations may view lower costs to be a primary consideration with labor quality as merely a secondary concern. It is hence understandable for firms in these sectors, particularly those with straightforward production processes, to pursue an extremely inexpensive labor force regardless of labor quality. Japanese firms' avoidance of inferior labor quality may be evolutionary, as Japanese FDI in China has clearly moved from being dominated by firms that are cost-driven to those that are more technology-intensive.

\section{CONCLUSIONS AND POLICY IMPLICATIONS}

This paper presents a new approach for testing and then verifying the existence of heterogeneity in disaggregate plant location choice situations. Japanese investors' location decision variations are empirically tested. This study finds that they appear to respond rather homogenously to location attributes in their plant location selection decisions in China. Varied responses do emerge around the concentrations of SOEs and labor quality. Most Japanese investors in China prefer low SOE concentration and high quality labor availability.

The lack of significant variations in Japanese investors' location decisions, particularly those toward policy variables, may suggest that existing policy incentives are insufficient to persuade Japanese firms to locate differentially; specifically, to locate outside highly FDIconcentrated coastal regions and into more inland and economically disadvantaged areas. More substantial incentives may therefore be needed to overcome the higher costs and risks associated with situating Japanese firms away from the coastal area to the western region. In addition, labor quality has emerged as an influential location factor, and any policy with a clear intention to improve labor quality would eventually be conducive to Japanese FDI attraction. These policy measures may include government financial support for education programs, favored polices to attract and treat well-educated professionals, education and training grants to enhance labor quality both for specific plant locations and more generally, and education-related facility construction. These policy options would be particularly critical to China's middle and western regions in order to prioritize their limited financial resources to harness the benefits of FDI on economic growth. 
Due to the existence of the Japanese nationality agglomeration, fiscal incentives or tax concessions initiated by provinces to draw FDI need not be a zero-sum game for China as a whole. In other words, fiscal incentives used to attract initial FDI could be well justified if the initial FDI could, in net, draw more FDI to the country. Thereby, the benefits delivered by the continued added FDI could eventually become greater than the inducements expended. Still there is the chance that a battle of incentives could ensue. The result in such a case would be greatly intensified interprovincial competition with respect to fiscal concessions. Such competition would undoubtedly dampen the national government's hopes of attracting FDI into western China, which is severely lacking in financial resources and means compared to its eastern counterparts. Thus, from a nationwide perspective, it is contradictory to both encourage eastern provinces to apply fiscal incentives for FDI and to pursue a western development strategy since the prior would draw FDI away from the nation's vast, poorer inland provinces. At least as long as FDI is rising rapidly nationwide, however, it is probably wise for national policies not to explicitly encourage or enable western provinces of China to apply special fiscal inducementsthose over or above those applied along the east coast-to attract FDI. This is because it is important for the Chinese national government to convey a message of fairness in its efforts to reduce regional economic disparities.

\section{REFERENCES}

Adamowicz, Wiktor, Joffre Swait, Peter Boxall, Jordan Louviere, and Michael Williams. (1997) "Perceptions versus Objective Measures of Environmental Quality in Combined Revealed and Stated Preference Models of Environmental Valuation,” Journal of Environmental Economics and Management, 32, 65-84.

Belderbos, Rene and Martin Carree. (2002) "The Location of Japanese Investments in China: Agglomeration Effects, Keiretsu, and Firm Heterogeneity,” Journal of the Japanese and International Economies, 16, 194-211.

Ben-Akiva, Moshe and Steven Lerman. (1985) Discrete Choice Analysis: Theory and Application to Travel Demand. MIT Press: Cambridge, MA.

Bhat, Chandra. (1998) “Accommodating Variations in Responsiveness to Level-of-Service Measures in Travel Mode Choice Modeling,” Transportation Research A, 32, 495-507.

Boxall, Peter and Wiktor Adamowicz. (2002) "Understanding Heterogeneous Preferences in Random Utility Models: A Latent Class Approach,” Environmental and Resource Economics, 23, 421-446.

Boxall, Peter, Wiktor L. Adamowicz, and Theodore Tomasi. (1996) “A Nonparametric Tests of the Traditional Travel Cost Model,” Canadian Journal of Agricultural Economics, 44, 183-193.

Broadman, Harry and Xiaolun Sun. (1997) “The Distribution of Foreign Direct Investment in China,” World Economy, 20, 339-361.

Brownstone, David and Kenneth Train. (1999) "Forecasting New Product Penetration with Flexible Substitution Patterns,” Journal of Econometrics, 89, 109-129.

Cassidy, John. (2002) Japanese Direct Investment in China: Locational Determinants and Characteristics. Routledge: New York

Southern Regional Science Association 2010. 
Chen, Chien-Hsun. (1996) "Regional Determinants of Foreign Direct Investment in Mainland China,” Journal of Economic Studies, 23, 18-30.

Cheng, Leonard and Yunn Kwan. (2000) "What Are the Determinants of the Location of Foreign Direct Investment? The Chinese Experience,” Journal of International Economics, 51, 379-400.

Cheng, Shaoming. (2006) "The Role of Labor Cost in the Location Choices of Japanese Investors in China,” Papers in Regional Science, 85, 121-138.

Cheng, Shaoming and Roger Stough. (2006) "Location Decisions of Japanese New Manufacturing Plants in China: A Discrete Choice Analysis,” Annals of Regional Science, 40, 368-387.

Coughlin, Cletus and Eran Segev. (2000a) "Foreign Direct Investment in China: A Spatial Econometric Study,” World Economy, 23, 1-23.

. (2000b) “Location Determinants of New Foreign-owned Manufacturing Plants,” Journal of Regional Science, 40, 323-351.

Daly, Andrew. (1982) "Estimating Choice Models Containing Attraction Variables," Transportation Research, 16, 5-15.

DeCoster, Gregory and William Strange. (1993) “Spurious Agglomeration,” Journal of Urban Economics, 33, 273-304.

Dunning, John. (1980) “Toward an Eclectic Theory of International Production: Some Empirical Tests,” Journal of International Business Studies, 11, 9-31.

. (1998) “Location and the Multinational Enterprises: A Neglected Factor?” Journal of International Business Studies, 29, 45-67.

Famulari, Melissa. (1995) “A Household-based, Nonparametric Test of Demand Theory,” Review of Economics and Statistics, 77, 372-382.

Ford, Stuart and Roger Strange. (1999) "Where do Japanese Manufacturing Firms Invest within Europe, and Why?” Transnational Corporations, 8, 117-142.

Friedman, Joseph, Daniel A. Gerlowski, and Johnathan Silberman. (1992) "What Attracts Foreign Multinational Corporations? Evidence from Branch Plant Location in the United States,” Journal of Regional Science, 32, 403-418.

Fu, Jun. (2000) Institutions and Investments: Foreign Direct Investment in China during an Era of Reforms. University of Michigan Press: Ann Arbor, MI.

Fung, Kwok-Chiu, Hitomi Iizaka, and Stephen Parker. (2002) "Determinants of U.S. and Japanese Foreign Direct Investment in China,” Journal of Comparative Economics, 30, 567-578.

Glasgow, Garrett. (2001) “Mixed Logit Models for Multiparty Elections,” Political Analysis, 9, 116-136.

Gong, Hongmian. (1995) “Spatial Patterns of Foreign Investment in China’s Cities, 1980-1989,” Urban Geography, 16, 198-209. 
Graham, Edward and Erika Wada. (2001) "Foreign Direct Investment in China: Effects on Growth and Economic Performance.” Peterson Institute for International Economics Working Paper WP01-3: Washington, DC.

Gross, Dominique, Horst Raff, and Michael Ryan. (2004) “Inter- and Intra-sectoral Linkages in Foreign Direct Investment: Evidence from Japanese Investment in Europe,” Journal of the Japanese and International Economies, 19, 110-134.

Hausman, Jerry and David Wise. (1978) “A Conditional Probit Model for Qualitative Choice: Discrete Decisions Recognizing Interdependence and Heterogeneous Preferences. Econometrica, 46, 403-426.

He, Canfei. (2003) "Location of Foreign Manufacturing in China: Agglomeration Economies and Country of Origin Effects,” Papers in Regional Science, 82, 351 - 372.

Head, Keith and John Ries. (1996) "Inter-city Competition for Foreign Investment: Static and Dynamic Effects of China's Incentive Areas,” Journal of Urban Economics, 40, 38-60.

Head, Keith, John Ries, and Deborah Swenson (1995) “Agglomeration Benefits and Location Choice: Evidence from Japanese Manufacturing Investments in the United States," Journal of International Economics, 38, 223-247.

. (1999) “Attracting Foreign Manufacturing: Investment Promotion and Agglomeration,” Regional Science and Urban Economics, 29, 197-218.

Hensher, David. (2005) Personal communication.

Hensher, David and William Greene. (2003) “The Mixed Logit Model: The State of Practice,” Transportation, 30, 133-176.

Hensher, David and Lester Johnson. (1981) Applied Discrete Choice Modeling. Halsted Press: New York.

Kogut, Bruce and Harbir Singh. (1988) "The Effect of National Culture on the Choice of Entry Mode,” Journal of International Business Studies, 19, 411-432.

Kojima, Kiyoshi. (1978) Direct Foreign Investment: A Japanese Model of Multinational Business Operations. Croom Helm: London.

Krugman, Pual and Anthony Venables. (1995) “Globalization and the Inequality of Nations," Quarterly Journal of Economics, 110, 857-880.

Kueh, Y. Y. (1992) “Foreign Investment and Economic Change in China,” China Quarterly, 131, 637-690.

Lecraw, Donald. (1993) "Outward Direct Investment by Indonesian Firms: Motivations and Effects,” Journal of International Business Studies, 24, 589-600.

Lee, Doowon and Youngrok Cheong. (1999) “Comparison of FDI into China between Korean Firms and Ethnic Chinese Firms,” Global Economic Review, 28, 28-53.

Little, Jane. (1978) “Locational Decision of Foreign Direct Investors in the United States,” New England Economic Review, 4, 43-63.

. (1980) "Foreign Direct Investment in the United States: Recent Locational Choices of Foreign Manufacturers,” New England Economic Review, 6, 5-22.

Southern Regional Science Association 2010. 
Louviere, Jordan, David A. Hensher, and Joffre D. Swait. (2000) Stated Choice Methods: Analysis and Applications in Marketing, Transportation and Environmental Valuation. Cambridge University Press: Cambridge, MA.

Lu, Minghong. (1997) Waiguo zhijie touzi quyu fenbu yu zhongguo touzi huanjing pinggu [Regional Allocation of Foreign Direct Investment and an Appraisal of China's Investment Environment]. Economic Research Journal, 12, 37 - 44. [In Chinese]

Luo, Yadong. (2000) "Project and Location Selection in China: Lessons from Foreign Companies,” in Frank-Jurgen Richter, ed., The Dragon Millennium: Chinese Business in the Coming World Economy. Quorum Books, Westport, NY, pp. 107 - 123.

Marshall, Alfred. (1920) Principles of Economics. Macmillan: London.

Massey, David. (2002) Heterogeneous Preferences in Random Utility Models of Recreation Demand. Unpublished doctoral dissertation, University of Delaware.

McFadden, Daniel and Keith Train. (2000) “Mixed MNL Models of Discrete Response," Journal of Applied Econometrics, 15, 447-470.

Morey, Edward, Robert Rowe, and Michael Watson. (1993) “A Repeated Nested-Logit Model of Atlantic Salmon Fishing,” American Journal of Agricultural Economics, 75, 578-592.

OECD (2002) Foreign Direct Investment in China: Challenges and Prospects for Regional Development. OECD publishing: Paris.

Ó Huallcháin, Breandán and Neil Reid. (1997) “Acquisition versus Greenfield Investment: The Location and Growth of Japanese Manufacturers in the United States,” Regional Studies, 31, 403-416.

Qu, Tao and Milford Green. (1997) Chinese Foreign Direct Investment: A Subnational Perspective on Location. Ashgate: Brookfield, VT.

Revelt, David and Keith Train. (1998) “Mixed Logit with Repeated Choices: Households' Choices of Appliance Efficiency Level," Review of Economics and Statistics, 80, 647657.

Schroath, Frederick, Michael H. Hu, and Haiyan Chen. (1993) "Country-of-origin Effects of Foreign Investments in the People's Republic of China,” Journal of International Business Studies, 24, 277-290.

Smith, Donald and Richard Florida. (1994) “Agglomeration and Industrial Location: An Econometric Analysis of Japanese-Affiliated Manufacturing Establishments in Automotive-related Industries,” Journal of Urban Economics, 36, 23-41.

Sun, Qian, Wilson Tong, and Qiao Yu. (2002) "Determinants of Foreign Direct Investment across China,” Journal of International Money and Finance, 21, 79-113.

Tokunaga, Suminori and Ryoichi Ishii. (2000) “An Empirical Analysis of Agglomeration Effects and Locational Choice of Japanese Electronics Firms in East Asia,” in Hirotada Kohno, Peter Nijkamp, and Jacques Poot (eds.), Regional Cohesion and Competition in the Age of Globalization. Edward Elgar: Northampton, MA. pp. 127-144.

Tong, Sarah and Angela Hu. (2003) "Do Domestic Firms Benefit from Foreign Direct Investment? Initial Evidence from Chinese Manufacturing,” unpublished paper presented 
at the Conference on China's Economic Geography and Regional Development, Hong Kong, December 15-16. Available on July 24, 2009, at http://www.hiebs.hku.hk/events_updates/pdf/tongyueting.pdf.

Toyo Keizai Inc. (2003) Kaigai Shinshutsu Kigyou Souran [Japanese Overseas Investments]. Toyo Keizai Inc.: Tokyo, Japan

Train, Kenneth. (1986) Qualitative Choice Analysis: Theory, Econometrics, and an Application to Automobile Demand. MIT Press: Cambridge, MA.

. (1998) "Recreation Demand Models with Taste Differences over People," Land Economics, 74, 230-239.

- (2003) Discrete Choice Methods with Simulation. Cambridge University Press: Cambridge, MA.

Wei, Yingqi and Xiaming Liu. (2001) Foreign Direct Investment in China: Determinants and Impact. Edward Elgar: Northampton, MA.

Wei, Yingqi, Xiaming Liu, David Parker, and Kirit Vaidya. (1999) “The Regional Distribution of Foreign Direct Investment in China,” Regional Studies, 33, 857-867.

Woodward, Douglas. (1992) "Locational Determinants of Japanese Manufacturing Start-ups in the United States,” Southern Economic Journal, 58, 690-708.

Yamawaki, Hideki. (1991) "Exports and Foreign Distributional Activities: Evidence on Japanese Firms in the United States,” Review of Economics and Statistics, 73, 294-300.

Zhang, Le-Yin. (1994) “Location-specific Advantages and Manufacturing Direct Foreign Investment in South China,” World Development, 22, 43-53.

Zhao, Hongxin and Gangti Zhu. (2000) "Location Factor and Country-of-Origin Differences: An Empirical Analysis of FDI in China,” Multinational Business Review, 8, 60-73.

Zhou, Changhui, Andrew Delios, and Jing Yu Yang. (2002) "Locational Determinants of Japanese Foreign Direct Investment in China,” Asia Pacific Journal of Management, 19, 63-86. 